Journal of Food Technology 9 (2): 61-65, 2011

ISSN: $1684-8462$

(C) Medwell Journals, 2011

\title{
Fatty Acids, Triacylglycerols, Carotenes, Retinols, Tocopherols and Phytosterols in Oils of Raphia sese and $R$. Laurentii from Congo-Brazzaville
}

\author{
${ }^{1}$ Seraphin Goteni, ${ }^{1}$ David Mampouya and ${ }^{1,2}$ Thomas Silou \\ ${ }^{1}$ Equipe Pluridisciplinaire de Recherche en Alimentation et Nutrition (EPRAN), \\ ${ }^{2}$ Ecole Superieure de Technologie des Cataractes (ESTcataractes), \\ Pole d Excellence Regional en Alimentation et Nutrition B.P. 368, Brazzaville, Congo-Brazzaville
}

\begin{abstract}
As part of a systematic evaluation of the technological potential of oil containing plants of the Congo basin, the oils of Raphia sese and R. laurentii from Congo-Brazzaville underwent a detailed physical and chemical study. These oils contained 37.0-38.5\% Palmitic acid (P), 33.0-34.0\% Linoleic acid (L), $19.5-21 \%$ oleic acid $(\mathrm{O}), 6.0-7.0 \%$ Stearic acid $(\mathrm{S})$ and $1.0-1.4 \%$ linolenic acid giving the following major triacylgycerols: 25.0-26.0\% Palmitoyloleoyllinoleoyl- (POL), $\quad 20.5-22.5 \% \quad$ Linoleoyldioleoyl- (LOO), $13.5-15.5 \%$ Palmitoyldilinoleoyl-(PLL), 9.0-11.0\% Palmitoyloleoylpalmitoyl-(POP), 8.5-10.0\% Palmitoyldioleoyl-(POO) and $8.5-10.0 \%$ trioleoyl- $(\mathrm{OOO})$ glycerols. The non-saponifiable fraction comprised large quantities of carotenes $(113 \mathrm{mg} / 100 \mathrm{~g})$, tocopherols $(33.0-54.0 \mathrm{mg} / 100 \mathrm{~g})$ with $\alpha$-tocopherol predominating $(32.0-47.0 \mathrm{mg} / 100 \mathrm{~g})$ and phytosterols (104.0-1 $47 \mathrm{mg} / 100 \mathrm{~g})$ including $88.0-120 \mathrm{mg} / 100 \mathrm{~g}$ of $\beta$-sitosterol. These results are evidence of an excellent nutritional quality and justify a posteriori the preference shown by local populations for the oil of Raphia sese (kolo) and R. laurentii (mbayaka) over palm oil.
\end{abstract}

Key words: Kolo, mbayaka, Raphia sese, Raphia laurentii, fatty acids, triacylglycerols, carotenes, retinols, tocopherols, phytosterols, Congo Basin

\section{INTRODUCTION}

Plant oils are of considerable political and economic importance with a world market worth $>32000$ million euros (Food Authenticity, 1998). Since 2004, six classical oils have dominated the production of plant-derived fats, accounting for some $90 \%$ of all oils: palm oil $(29.5 \%)$, soy oil $(28 \%)$, rapeseed oil $(14.6 \%)$, sunflower oil $(8.8 \%)$, cottonseed oil $(3.9 \%)$ and groundnut oil $(3.5 \%)$. The remaining $10 \%$ comprise palm kernel, copra, olive, corn and other longstanding oils. Given the importance of the trade deficit in culinary oils in Congo-Brazzaville there is a need to promote local oils already consumed locally and which are of demonstrable nutritional utility.

The species of the genus Raphia were once considered to be a source of oil as promising as the oil palm Elaeis guineensis. Unfortunately they are known and exploited only by the local populations in the areas where they grow naturally.

The raffia palm has multiple uses. Its fermented sap yields a drink much valued by the local populations. Its roots, associated with other ingredients are used in the traditional pharmacopoeia. The bark of its trunk is used to cover the walls of huts while the heartwood of dried timber is used to make small items of furniture, musical instruments and children's toys.
The central bud either raw or cooked is an excellent dietary vegetable. The leafy parts of the fronds are assembled to thatch the roofs of dwellings while the veins are used to make brooms. The fibres extracted from the fronds are woven into raffia matting. The oils from the fruit pulp are used for culinary purposes or as a skin ointment. Traditional medical practitioners recognise their moisturising, nourishing, healing and stimulating properties.

Despite their evident utility, the raffia palm has not prompted much phytochemical research. Most studies have focused on the oil extracted from the pulp and the analytical work carried out has seldom gone beyond determining physical and chemical indices and fatty acid composition. These studies have concerned oils from Nigeria (Otedoh, 1974), Congo-Brazzaville and CongoKinshasa.

The study reported here presents the most complete analysis carried out to date on these oils. The purpose was to determine, under strictly identical conditions and for two raffia species (Raphia sese and $R$. laurentii) the density, viscosity, refractive index, acid index, iodine index and saponification index of the oil extracted from the pulp, together with its content of fatty acids, triacylgylycerols, carotenes, retinols (vitamin A),

Corresponding Author: Thomas Silou, Equipe Pluridisciplinaire de Recherche en Alimentation et Nutrition (EPRAN), Pole d Excellence Regional en Alimentation et Nutrition B.P. 368, Brazzaville, Congo-Brazzaville 
tocopherols (vitamin E) and phytosterols, in order to highlight the nutritional utility and technological potential of this resource which is very abundant in the swamp forests of the Congo Basin.

\section{MATERIALS AND METHODS}

Plant material: The raffia palm belongs to the branch of spermaphytes, sub-branch angiosperms, class monocotyledons, super-order Spadiciflores order Palmae, family Palmaceae, subfamily Lepidocaryoids, genus Raphia. The taxonomy is not very precise at the species level in Africa. The two species we are concerned with in this research are $R$. sese and $R$. laurentii (locally olenguet and ibuu in the mbosi language). They, respectively supply oils locally called kolo (red, reddish-orange oil) from $R$. sese and mbayaka (yellowish slightly orange oil) from $R$. laurentii. Both species grow naturally in the swamp forests of the Congo Basin. They differ in their size: $R$. sese possesses a thin, slender trunk 8-12 $\mathrm{m}$ high with deciduous leaves and long hanging fibres. The trunk of $R$. laurentii is short and stout, 3-6 $\mathrm{m}$ high with sheaths and persistent foliar petioles. Both trunks have pennate fronds, upright and leaning outward at their ends, short for $R$. sese and long for $R$. laurentii bearing spiny petioles. The fruits of both species are globular berries covered with interlocking scales, initially green and turning red as they ripen for $R$. sese and yellow for R. laurentii.

Extraction of oil by the traditional method: Ripe raffia fruit were heaped and covered with leaves. After 6-14 days to let the pulp soften the scales were easily separated from the fruit. The pulp was then pummelled in water to separate it from the kernel. The pulp was pounded in water and the liquid phase was then decanted from the solid phase. The solid cake was discarded and the oil containing aqueous phase was heated in a pot to boiling point. Compact aggregates were formed at the bottom of the vessel. The oil was collected after a second decantation

Extraction of the oil using the soxhletapparatus: The oil was extracted from the pulp using a Soxhlet apparatus. The fresh fruit pulp, scaled and separated from the kernel was crushed in a mortar and placed in a Soxhlet apparatus. The oil was extracted with hexane for $8 \mathrm{~h}$ at $80^{\circ} \mathrm{C}$ and the solvent evaporated in a rotary evaporator (Set Evaporator LR GI). The oil obtained was oven-dried at $100^{\circ} \mathrm{C}$ for $24 \mathrm{~h}$ to eliminate traces of solvent.

Determination of physical and chemical characteristics: Acid, iodine and saponification indices (AI, II and SI) of kolo and mbayaka oils were determined using AFNOR standard methods.
Density at $20^{\circ} \mathrm{C}$ was measured using an automatic densimeter (Anton Paar DMA 35N Standard).

Viscosity was measured using an automatic capillary viscosimeter with photoelectric detection (AVS470, Schott Instruments). Refractive index was measured using an automatic refractometer (AR60, Reichert).

\section{Analysis of chemical composition of oils}

Analysis of Fatty Acids (FA): Fatty acids were analysed by gas phase chromatography after methylation using an Agilent 6890 series gas chromatograph fitted with a Supelcowax 10 capillary column (SGE, Courtaboeuf, France) $30 \mathrm{~m}$ long of internal diameter $0.32 \mathrm{~mm}$ with a film thickness of $0.25 \mu \mathrm{m}$. The fatty acids were injected in the form of methyl esters. The carrier gas was helium with a flow rate of $1 \mathrm{~mL} \mathrm{~min} \mathrm{~m}^{-1}$ and the split ratio was $1 / 100$. The injector temperature was $250^{\circ} \mathrm{C}$. The flame ionisation detector temperature was $270^{\circ} \mathrm{C}$. The temperature program was: $130^{\circ} \mathrm{C}$ for $2 \mathrm{~min}, 5^{\circ} \mathrm{C} \mathrm{min}^{-1}$ ramp to $225^{\circ} \mathrm{C}$ then hold for $7 \mathrm{~min}$.

The chromatograms were recorded using a microcomputer with Chemstation-Agilent data processing software.

Analysis of Triacylglycerols (TAG): Triacylglycerols were assayed using a Thermo Fisher HPLC set in reverse phase with two C18-grafted silica columns in series $(24 \times 0.4 \mathrm{~cm})$ and a light diffusion detector (Alltech). The chromatograms were recorded using a microcomputer with Azur data processing software.

Analysis of carotenes and retinols (vitamin A): Carotenes were analysed by colorimetry using a spectrometer (25-450 nm, Perkin Elmer Lambda).

The assay of vitamin $\mathrm{A}$ in retinol equivalent was carried out by high performance liquid chromatography according to the standard NF EN 12823-1 with external calibration with all-trans retinol and quantification of vitamin $\mathrm{A}$ as retinol (cis+trans) and in the following experimental conditions: column Kromasil $250 \times 4.6 \mathrm{~mm}$, $5 \mu \mathrm{m}$, mode isocratic mode with a flow rate of $1.2 \mathrm{~mL}$ $\mathrm{min}^{-1}$, mobile phasehexane/ isopropanol (98/2), JASCO fluorimetric detector, injected volume $10 \mu \mathrm{L}$. The chromatograms were recorded using a microcomputer with Chromquest 4.1 data processing software (ThermoFisher).

Analysis of tocopherols (vitamin E): Tocopherols were assayed according to standard ISO 9936 using a ThermoFisher HPLC with a silica column $(25 \times 0.4 \mathrm{~cm})$ and 
a ThermoFisher FL 3000 spectrofluorimetric detector. The chromatograms were recorded using a microcomputer with Chromquest 4.2 data processing software (ThermoFisher).

Analysis of phytosterols: Phytosterols were analysed by gas phase chromatography after saponification and purification by thin layer chromatography with a Thermo Quest GC 8000 chromatograph equipped with an apolar DBI column ( $100 \%$ dimethylsiloxane) $15 \times 0.25 \mathrm{~mm}$ the oven temperature was programmed at $220^{\circ} \mathrm{C}$ the injector temperature was $300^{\circ} \mathrm{C}$ and the detector temperature was $310^{\circ} \mathrm{C}$. The carrier gas was helium with a flow rate of $6 \mathrm{~mL} \mathrm{~min}^{-1}$. The chromatograms were recorded using a microcomputer with Chemstation-Agilent data processing software.

\section{RESULTS AND DISCUSSION}

Oil content: Using the Soxhlet apparatus the oil was extracted from $R$. sese with a yield of $54 \%$ against $47 \%$ for R. laurenti (Table 1). With the traditional method, these yields were respectively 23 and $14 \%$, i.e., an extraction rate of the order of $29.8 \%$ for $R$. laurenti and $42.6 \%$ for $R$. sese. These two species can be considered as major oil-bearing plants like the oil palm (Elaeis guineensis).

Physical and chemical characteristics: The acid index for the oil extracted by the traditional method was twice that extracted with the Soxhlet apparatus (Table 1). However, at about 4 , this value remains low compared with those found in the literature for crude African oils which can

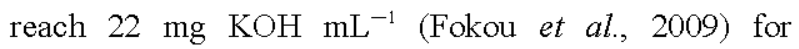
Cucurbitaceae.

The acid index which accounts for the free fatty acids present in the oil is responsible for the acidity and oxidation proneness of the oil; it is thus an indicator of oil quality. With an acid index of about 2 , the oil extracted with the Soxhlet apparatus was of better quality than that obtained by the traditional method. The time needed for the natural softening of the pulp which is an essential part of the traditional process and which can take several days, doubles the quantity of free fatty acids present in the oil.

The other characteristics hardly varied between methods or species two very similar oils were obtained. Also, the values obtained for all the characteristics were close to those of other common culinary oils.

Fatty acids: Out of 12 identified fatty acids three with individual levels $>19 \%$ made up $>90 \%$ of the total fatty acids (Table 2). Palmitic acid (C16: 0), a saturated fatty acid, the main constituent of palm oil was the main one
Table 1: Yeild, physical and chemical characteristics of $R$. laurentii and $R$. sese oils

\begin{tabular}{lll}
\hline Species & R. laurentii & R. sese \\
\hline Oil $(\%)$ & 47 & 54 \\
Density $\left(20^{\circ} \mathrm{C}\right)$ & $0.912(0.006)$ & $0.915(0.005)$ \\
Viscosity $\left(20^{\circ} \mathrm{C}\right)$ & $25.82(0.08)$ & $26.00(0.10)$ \\
Refraction index & $1.4650(0.0005)$ & $1.4655(0.0005)$ \\
Acid index & $2.6(0.4)$ & $2.2(0.1)$ \\
Saponification index & $222(8)$ & $226(11)$ \\
Iodine index & $82(0.6)$ & $81(0.6)$ \\
\hline
\end{tabular}

Table 2: Fatty acid content of $R$ sese and $R$. laurentii oils

\begin{tabular}{lrr}
\hline Fatty acids contents (\%) & R laurentii & R. sese \\
\hline C14: 0 & 0.20 & 0.26 \\
C16: & 38.40 & 37.42 \\
C16: $1(\mathrm{n}-7)$ & 0.12 & 0.14 \\
C18: & 6.22 & 7.00 \\
C18: $1(\mathrm{n}-9)$ & 19.54 & 20.84 \\
C18: $2(\mathrm{n}-6)$ & 33.82 & 32.90 \\
C18: $3(\mathrm{n}-6)$ & 1.42 & 1.14 \\
C18: 3 (n-3) & 0.02 & 0.02 \\
C20: 0 & 0.10 & 0.10 \\
C20: 1 (n-11) & 0.10 & 0.10 \\
C22: 0 & 0.02 & 0.03 \\
C24: 0 & 0.04 & 0.05 \\
$\sum$ sat & 44.98 & 44.86 \\
insat & 55.02 & 55.14 \\
R & 1.20 & 1.20 \\
\hline R & &
\end{tabular}

$\mathrm{R}=$ इinsat $/$ sat

in raffia oil with a content of about $38 \%$ against $>50 \%$ in palm oil and safou oil. This observation points to a better quality of the raffia oils studied given also the following features.

Linoleic acid (C 18: 2 (n-6)) an essential fatty acid, came second with a content of $34 \%$ in both oils. This acid which is involved in the regulation of cholesterol levels, reduces the risk of cardiovascular accidents.

The third acid, oleic acid (C18: 1 (n-9)) accounts for some $20 \%$. Like linoleic acid, it is involved in cholesterol regulation.

Two minor constituents complete the profile of the oils studied: stearic acid (C18: 0) (6-7\%) a saturated fatty acid and linoleic acid (C18: $3(n-3))(1 \%)$ an essential polyunsaturated fatty acid. The ratio of unsaturated to saturated fatty acids which was 1.2 , irrespective of the species treated and the process used was slightly higher than that found for palm oil (1.0) but much higher than for palm kernel oil (0.3).

Triacylglycerols: For the two species studied and irrespective of the method used to extract the oil (Table 3), we were able to identify 14 TAGs essentially made up of the major acids identified by gas phase chromatography $(\mathrm{P}, \mathrm{L}, \mathrm{O}, \mathrm{S})$. These TAGs included 6 major TAGs $(>8 \%), 3$ minor TAGs $(1-4 \%)$ and 5 trace TAGs $(<1 \%)$. This result is very close to that obtained in a study in progress on 
Table 3: Triacyiglycerol content (\%) of R. laurentii and R. sese oils

\begin{tabular}{lcr}
\hline & Content (\%) & \\
& R. laurentii & R. sese \\
Triacyglycerols & 2.3 & 3.3 \\
OLL & 13.5 & 15.4 \\
PLL & 1.7 & 2.5 \\
LnOP & 20.7 & 22.6 \\
LOO & 25.8 & 25.1 \\
POL & 0.7 & 0.1 \\
PPL & 10.2 & 8.1 \\
OOO & 9.8 & 8.4 \\
POO & 10.8 & 9.4 \\
POP & 0.1 & 0.1 \\
PPP & 1.0 & 0.9 \\
SOO & 0.6 & 0.7 \\
POS & 2.7 & 3.3 \\
PSS & 0.1 & 0.1 \\
SOS & &
\end{tabular}

P S O L Ln

Table 4: Carotene, tocopherol, tocotrienol, sterol contents (\%) of $R$. laurentii and $R$ sese oils

\begin{tabular}{|c|c|c|}
\hline Contents & R. lourentii & R. sese \\
\hline Carotene $\left(\mathrm{mg} \mathrm{kg}^{-1}\right)$ & 5.6 & 113.0 \\
\hline Vitamin A ( $\mu \mathrm{g}$ Eq. Retinol/100g) & 28.0 & 46.0 \\
\hline \multicolumn{3}{|l|}{ Tocopherol (mg kg $\left.{ }^{-1}\right)$} \\
\hline$\alpha$ & 315.0 & 466.0 \\
\hline$\beta$ & 68.0 & 21.0 \\
\hline$\gamma$ & 0.0 & 0.0 \\
\hline$\Delta$ & 2.0 & 6.0 \\
\hline \multicolumn{3}{|l|}{ Tocotrienol $\left(\mathrm{mg} \mathrm{kg}^{-1}\right)$} \\
\hline$\alpha$ & 40.0 & 26.0 \\
\hline$\beta$ & 0.0 & 16.0 \\
\hline$\gamma$ & 6.0 & 30.0 \\
\hline \multicolumn{3}{|l|}{ Sterols (mg $100 \mathrm{~g}^{-1}$ ) } \\
\hline Compesterol & 6.2 & 11.0 \\
\hline Stigmasterol & 9.0 & 16.7 \\
\hline$\beta$-Sistosterol & 91.4 & 126.0 \\
\hline$\Delta 5$ avenasterol & - & 2.2 \\
\hline
\end{tabular}

the evaluation of the biodiversity of raffia oils from Congo-Brazzaville, conducted on a larger number of oils. It identified 4 major TAGs (PLL, POL, PPL, PSL), 3 minor TAGs (OLL, OOL, POO) and 8 trace TAGs (LLL, PLLn, OOO, PPP, SSO, PSO, PPS, SOO).

Carotenes and vitamin A: Like palm oil, the raffia oils studied were coloured shades of red owing to the carotenes they contain. The oil of $R$. sese which was dark red had a carotene content of $113 \mathrm{mg} / 100 \mathrm{~g}$, close to that of palm oil which contains $120 \mathrm{mg} / 100 \mathrm{~g}$ (Table 4). The yellowish oil of $R$. laurentii contained very small amounts of carotenes $(5.6 \mathrm{mg} / 100 \mathrm{~g})$. These observations hold for both the traditional and the Soxhlet. extraction method. The vitamin 2 content in oil from $R$. laurentii was about half that in oil from $R$. sese.

Finally, kolo oil contained 20 times less carotenes and twice more vitamin A than mbayaka oil. It is more similar to palm oil which it could replace as a source of carotenes and vitamin $\mathrm{A}$.
Tocopherols and tocotrienols: The oil of Raphia sese contained more total tocopherols than oil of $R$. laurentii (about $56 \mathrm{mg} / 100 \mathrm{~g}$ against about $43 \mathrm{mg} / 100 \mathrm{~g}$ of total oil (Table 4). These values are much higher than those found for palm oil ( $30 \mathrm{mg} / 100 \mathrm{~g}$ of total oil). Of the 4 isomers present $(\alpha-, \beta-, \gamma-$ and $\Delta$-tocopherol) $\alpha$-tocopherol predominates. The tocopherols or $\mathrm{E}$ vitamins are endogenous antioxidants for plant oils and so from this point of view the oil of $R$. sese is better protected from auto-oxidation than that of $R$. laurentii and both are better protected than palm oil. Tocopherols, carotenes, ascorbic acid or vitamin $\mathrm{C}$ and polyphenols form the four main plant antioxidants. They help to neutralise free radicals and so play an essential role in the protection of human cell membranes (Machlin, 1980; Burton and Ingold, 1986).

Phytosterols: Campesterol, sigmasterol, $\beta$-sitosterol and $\Delta$-aveasterol were found in the oils of Raphia sese and $R$. laurentii; $\beta$-sitosterol predominated in both oils with respectively 126 and $91 \mathrm{mg} / 100 \mathrm{~g}$ of total oil (Table 4) we note the absence of cholesterol. In the body, phytosterols diminish the absorption of cholesterol and thus help to lower LDL (or bad cholesterol).

\section{CONCLUSION}

The hexane extraction of oil from the pulp of the raffia fruit in a Soxhlet apparatus gave an oil content of $54 \%$ for kolo from Raphia sese and about $47 \%$ for mbayaka from $R$. laurentii. By contrast, the extraction of oil from pulp by the traditional method gave a yield of only $23 \%$ of kolo and $14 \%$ of mbayaka.

Except for the acid index which was high for the oils extracted by the traditional method, the other indices showed similar values for oils extracted by hexane in the Soxhlet apparatus and for those extracted in the traditional way. Density, refractive index and iodine index show that kolo and mbayaka oils can be classified among the non-drying oils. Their high essential fatty acid and antioxidant contents support their reputation among the local populations, who consider them very high quality culinary oils and who prefer them to palm oil for their nutritional qualities and also for their use in traditional pharmacy and cosmetics.

\section{ACKNOWLEDGEMENTS}

Researchers are grateful to G. Piombo and co-workers at CIRAD Montpellier (France) for confirming analytical 
results for fatty acids, triacylglycerols, carotenes, tocopherols and phytosterols and to F. Dejean and co-workers at ITERG Pessac (France) for confirming vitamin A analyses.

\section{REFERENCES}

Burton, G.W. and K.U. Ingold, 1986. Vitamin E: Application of the principles of physical organic chemistry to the exploration of its structure and function. ACC. Chem. Res., 19: 194-201.
Fokou, E., M.B. Achu, G. Kansci, R. Ponka, M. Fotso, C. Tchiegang and F.M. Tchouanguep, 2009. Chemical properties of some cucurbitaceae oils from Cameroon. Pak. J. Nutr., 8: 1325-1334.

Food Authenticity, 1998. Issues and methodologie. FAIM. Concerted Action, No. AIR3-CT94-2452, Eurofins Scientific, pp: 214-257.

Machlin, L.J., 1980. Vitamin E: A Comprehensive Treatise. Marcel Dekker, New York, USA., ISBN-13: 9780824768423, pp: 660.

Otedoh, M.O., 1974. Raphia oil: Its extraction, properties and utilization. J. Nig. Inst. Oil Palm Res., 5: 45-49. 